\title{
GLOBALIZACIÓN, IDENTIDAD SOCIAL Y HÁBITOS ALIMENTARIOS
}

\section{GLOBALIZATION, SOCIAL IDENTITY AND FOOD HABITS}

\author{
Francisco Entrena Durán*
}

\section{RESUMEN}

Partiendo del hecho de la producción y reproducción social de los hábitos alimentarios, el autor analiza sociológicamente algunos efectos de la globalización socioeconómica sobre esa producción y reproducción. Particularmente, el artículo se centra en el influjo de la globalización sobre la pérdida de la soberanía alimentaria y la desterritorialización del consumo y cultivo de alimentos, así como en sus efectos sobre la alimentación como factor de construcción de la identidad y de diferenciación social.

PALABRAS CLAVE: ALIMENTACIÓN * NUTRICIÓN * CALIDAD DE LOS ALIMENTOS * GLOBALIZACIÓN * IDENTIDAD CULTURAL * CLASES SOCIALES

\section{ABSTRACT}

By taking into account the fact of the food habit's social production and reproduction, the author studies sociologically some outcomes of present-day socio-economic globalization on the said production and reproduction. Particularly, the article focuses on both the impact of globalization on the so-called "losing of food sovereignty" and the deterritorialization of food consumption and production, as well as in its effects on feeding, which is understood as a factor of identity and social differentiation.

KEY WORDS: FEEDING * NUTRITION * FOOD QUALITY * GLOBALIZATION * CULTURAL IDENTITY * SOCIAL CLASSES

\section{INTRODUCCIÓN}

Los hábitos alimentarios se producen y reproducen socialmente; es decir, son construcciones sociales, al igual que la generalidad de las actividades o realidades sociales significativas para los sujetos humanos (Berger y Luckmann: 1979). Desde luego, esto no significa que se ignore el carácter natural o biológico del hecho de nutrirse. Lo que pasa es que, ya desde los más remotos orígenes de la humanidad, antes incluso del descubrimiento 
humano de la posibilidad de cocinar o transformar determinados productos de la naturaleza para alimentarse, desde el momento mismo en que la ingestión de tales productos es dotada de un sentido por parte de quiénes los consumen, puede considerarse que el hecho natural de comer ha sido revestido de una significación sociocultural.

La persistente dificultad de deslindar nítidamente entre lo social y lo natural está en el origen de los reiterados debates que se han suscitado en el ámbito de las Ciencias Sociales acerca de ello. Una consecuencia de tales debates es que los significados y el peso relativo atribuidos a cada uno de los dos polos del binomio naturaleza/sociedad han variado a lo largo de la historia $y$ difieren de unos contextos socioculturales a otros. De todas formas, como tendencia evolutiva general, puede afirmarse que, a medida que con el tiempo se han ido ampliando la envergadura y los efectos de la acción humana sobre el entorno natural, se ha experimentado una creciente preponderancia de lo sociocultural sobre lo natural.

Es más, la propia naturaleza se ha ido modificando como consecuencia de la paulatina influencia de lo social sobre ella, por lo que puede hablarse de una especie de construcción social de la naturaleza (Eder: 1996). Esto se manifiesta, por ejemplo, en las adaptaciones biológicas experimentadas por un gran número de seres humanos adultos de cara a tolerar sin problemas el consumo de leche de vaca, cabra, camella y otros herbívoros. Problemas que, evidentemente, nunca han tenido los humanos en lo relativo al consumo de la leche materna en sus primeras fases de vida. Dicha leche es el alimento ideal, tanto por su gran valor nutricional e inmunológico para el recién nacido (Riverón-Corteguera: 1995), como por el hecho de que este nace con todas las enzimas y mecanismos necesarios que permiten su absorción $y$ metabolismo. Sin embargo, los miembros adultos de las sociedades que domesticaron herbívoros mansos, para poder consumir la leche de estos, tuvieron que desarrollar en su organismo la capacidad de sintetizar la lactasa; es decir, la enzima que descompone el azúcar de la leche en glucosa y galactosa $y$ hace posible su metabolismo en el intestino. Este hecho invalida la idea, $\tan$ generalizada en nuestro contexto, de que la leche de los herbívoros es el mejor alimento natural, pues la normalización de su consumo es el resultado de un proceso social que no se ha experimentado en otras sociedades, como, por ejemplo, entre los aborígenes americanos, australianos o de las islas del sur del Pacífico; ni tampoco entre los nativos del norte y el sudeste de Asia o en China y Japón, donde se domesticaron cerdos en vez de vacas, por lo que han de buscar en otras fuentes alimentarias el calcio, la vitamina D y otros factores contenidos naturalmente en la leche que ayudan a la absorción de este mineral y que necesita el organismo. De ahí, que la "naturaleza" de estas poblaciones no se haya adaptado a beber leche líquida, sino previamente trasformada o predigerida en forma de queso o yogur, ya que la leche fresca les ocasiona efectos desagradables, por lo que no la incluyen entre sus preferencias alimentarias (Flichtentrei: 2006).

Ya antes de nacer empiezan a construirse socialmente las "inclinaciones naturales" relativas al gusto de cada individuo, según las diferenciadas actitudes al respecto de su clase o grupo social de pertenencia. Así, como señala Patricia Aguirre, de manera inmadura, en el líquido amniótico "se aprende a gustar", porque su composición cambia en función del tipo de alimentos que ingiere la madre; posteriormente, en el periodo de la lactancia, el sabor de la leche materna experimenta cambios sutiles según la ingesta materna (Aguirre citada por Flichtentrei: 2006).

Por lo tanto, ya desde sus épocas más tempranas, el niño comienza a interiorizar el universo gustativo característico de la situación social de su familia, con lo que la formación de algo tan aparentemente "natural" como es el gusto, entendido como la propensión a consumir unos determinados alimentos $y$ a rechazar otros, es un hecho más que contribuye a la reproducción de las diferentes posiciones sociales.

En tanto que resultado de un proceso de construcción social, la formación del gusto lleva al despliegue de una serie de prácticas y actitudes sociales relativas, por ejemplo, a cómo percibimos el medio ambiente, a cómo producimos 
los alimentos (o sea, a la tecnología y los procedimientos que usamos para ello) o "a qué cosas decidimos considerar como alimentos y a cuáles otras como no comestibles". En suma, se trata de todas esas prácticas y actitudes sociales que nos llevan a decidir qué es el "buen comer" o el "mal comer", las cuales, de esta forma, legitiman nuestras preferencias y aversiones alimentarias. Preferencias y aversiones que no se fundamentan sólo en las cualidades nutricionales de los alimentos, sino también, en muy gran medida, en las significaciones culturales atribuidas a ellos y/o a su consumo por los grupos sociales de pertenencia o referencia que han conformado y conforman el proceso de socialización alimentaria de los sujetos.

\section{GLOBALIZACIÓN Y PÉRDIDA DE LA SOBERANÍA ALIMENTARIA}

Hace ya tiempo que, debido al creciente desarrollo de los intercambios comerciales transnacionales, el consumo alimentario ha dejado de estar mayoritariamente limitado a los cultivos propios de cada país o territorio local. La globalización socioeconómica ha conllevado una paulatina deslocalización y desestacionalización de las dietas, y a la vez a la extensión de hábitos de consumo cada vez más parecidos a escala planetaria. Esto ocasiona dos efectos contradictorios en la alimentación: de una parte, la creciente homogeneización mundial de las dietas y de las actitudes socioculturales ante ellas (Díaz-Méndez y Gómez-Benito: 2001), y, de otra, una búsqueda de la diversidad, que tiende a intensificarse precisamente como reacción frente a dicha homogeneización. En cualquier caso, las consecuencias homogeneizadoras de la globalización sobre la alimentación son preponderantes en un grado tal que acaban, con frecuencia, por mermar seriamente el grado de soberanía alimentaria de los actores sociales de los contextos locales.

La soberanía alimentaria es entendida aquí en el mismo sentido en que lo hace la organización "Vía Campesina", que la define como "el derecho de los pueblos, de sus países o uniones de estados, a definir su política agraria y alimentaria sin dumping frente a países terceros". El concepto de soberanía alimentaria, que fue desarrollado por Vía Campesina y situado en el debate público con ocasión de la Cumbre Mundial de la Alimentación celebrada en 1996, trata de ofrecer una alternativa a las políticas neoliberales de globalización. La esencia de la soberanía alimentaria, según Vía Campesina, sería priorizar la producción autóctona y la protección de los productores locales frente a las políticas de exportación y de apertura comercial características del neoliberalismo (Vía Campesina, 2003).

En razón de esto, se considera aquí que existe soberanía alimentaria cuando la determinación y el abastecimiento de las demandas de alimentos de la población tienen lugar a partir de la producción específica de un determinado ámbito nacional, regional o local, respetando la biodiversidad productiva y cultural. Para garantizar su soberanía alimentaria, es preciso que dicho ámbito controle autónomamente la producción y la comercialización de los alimentos, a la vez que se requiere de la promoción de prácticas y tecnologías agrarias que aseguren la preservación de la biodiversidad y la protección de las producciones locales, regionales o nacionales. Asimismo, es fundamental establecer políticas agrarias capaces de crear unas condiciones socioeconómicas y normativas adecuadas para un acceso justo $y$ equitativo al agua, la tierra, los recursos energéticos y los mercados. La inexistencia de estas condiciones en Latinoamérica, junto con los procesos de globalización neoliberal implementados en ella desde las dos últimas décadas del siglo Xx, han contribuido sobremanera a que varios países de este continente estén desarrollando una agricultura sobre todo para la exportación, mientras que tienen que importar para su consumo considerables cantidades de alimentos básicos para su dieta cotidiana (como por ejemplo, en México, el frijol o el maíz) en cuya producción tradicionalmente han sido autosuficientes. Como consecuencia, esos países sufren una progresiva reducción de su soberanía alimentaria, ya que el abastecimiento alimentario de sus poblaciones está cada vez más en manos de una serie de empresas transnacionales fuera de su control. 
En esta situación, en aras de la liberalización mundial del comercio, se están aplicando, tanto en Latinoamérica como en otras partes del planeta, políticas económicas de ajuste que están destruyendo o amenazando seriamente las capacidades productivas de las sociedades locales, regionales o nacionales y acarreando la globalización del hambre y de la pobreza. Como reacciones frente a ello, están surgiendo crecientes reivindicaciones en defensa de la biodiversidad y la soberanía alimentaria, por parte de diversas poblaciones nacionales, regionales o locales. Tales reivindicaciones emergen cuando muchos son conscientes de que hay que implementar los medios y los controles colectivos apropiados para asegurar el autoabastecimiento y la seguridad alimentaria de la población. De una parte, con referencia al autoabastecimiento, dichos controles contribuirían a evitar problemas como, por ejemplo, la sobreexplotación de especies marítimas, su consiguiente agotamiento, ruptura de las cadenas tróficas y depredación de las aguas. Por otra parte, en lo relativo a la seguridad alimentaria, hay que destacar la importancia del hecho de idear controles de los sistemas de producción alimentaria (Arribas: 2005), los cuales son una de las mejores estrategias para actuar contra los riesgos y la aparición y/o expansión de las enfermedades relacionadas con ciertas maneras actuales de producir alimentos como, por ejemplo, la agricultura dependiente de los agroquímicos, que conduce a la contaminación de los acuíferos (Beck: 1993; Fereres: 1993; Vera y Romero: 1994, Altieri y Nicholls: 2002).

El control colectivo democrático de los procesos de producción alimentaria y el que estos sean cada vez más transparentes se hacen hoy especialmente necesarios, ya que dichos procesos resultan, a menudo, muy difíciles de comprender $y$ vigilar por la población, debido a su creciente complejidad como consecuencia de la progresiva complejidad de unos sistemas agroalimentarios cada vez más industrializados a escala global (Machado y Torres: 1987; Mcmichael: 1994). Esto propicia unas formas de producción, conservación y comercialización de los alimentos que nos abocan a confiar a los expertos en nutrición y salud (cuyo lenguaje, a menudo, no es fácilmente entendible por el común de la gente) el control de "eso" que la agroindustria nos vende como comida ${ }^{1}$. Como consecuencia, la agroindustria y sus canales mediáticos han reemplazado a la experiencia artesanal común de las poblaciones tradicionales respecto a cómo producir y consumir alimentos.

Todo esto acontece en un contexto socioeconómico global, en el que tiene lugar una paulatina extensión del mercado de los platos precocinados, de los potencializadores de sabor, de los conservantes $y$ de otras diversas sustancias que manifiestan unos procesos más complejos de elaboración de los alimentos, ya sea con fines de asegurar su conservación, facilitar su cocinado o con propósitos meramente estéticos, de cara a buscar nuevas presentaciones del producto. Ello redunda en una gradual pérdida de autonomía de los consumidores en lo que se refiere a la determinación de sus hábitos alimentarios, los cuales incrementan progresivamente sus niveles de dependencia respecto a lo que marcan las transnacionales alimentarias, con una gran capacidad para divulgar, cuando no imponer de facto, mediante la publicidad $y / 0$ el monopolio de los mercados alimentarios, criterios de presentación o envasado de los productos, a la vez que procuran el establecimiento de unos modelos y cotas de producción alimentaria acordes con el

1 A este respecto, la tesis doctoral de Mohammed Karim Hassouan, investigador del Departamento de Química Analítica de la Universidad de Granada, dirigida por los profesores José Luís Vílchez Quero, Alberto Navalón Montón y Oscar Ballesteros García, ha demostrado la presencia de quinolonas (el grupo más importante de antibióticos sintéticos utilizados en medicina humana y veterinaria actualmente) en alimentos, tales como el huevo de gallina, la leche de vaca, la carne de pollo, de ternera o de cerdo, y en el hígado de cerdo. Ello provoca en el ser humano efectos tóxicos, desarrollo de resistencia bacteriana e hipersensibilidad alérgica; pero, además, ocasiona problemas ambientales (contaminación de aguas y suelos) e industriales (producción de queso, mantequilla o yogurt). (Revista Campus, UGR, nro. 246, página 10, 2007). 
mantenimiento de niveles de precios en consonancia con sus intereses.

Hemos llegado a una situación en la que el problema básico no es ya obtener alimentos suficientes para garantizar la nutrición de la población existente, sino asegurar su equilibrada producción $y$ distribución por la generalidad del planeta. En este contexto, de habitual superproducción de las agriculturas de los países avanzados, la persistencia de preocupantes muestras de desnutrición y de hambrunas reiteradas, sufridas por una considerable parte de la población mundial, evidencian que la seguridad alimentaria (entendida como el derecho a recibir la alimentación cuantitativa y nutricionalmente adecuadas) no depende sólo de la suficiencia de alimentos, sino también, muy especialmente, de las posibilidades que ofrecen las estructuras socioeconómicas y políticas en lo relativo a asegurar el acceso a los alimentos para la generalidad de la población que las integra (Molina: 2002). Posibilidades que dependen, en muy gran medida, de los mayores o menores niveles de equidad en la distribución de las riquezas, lo cual está ligado al desarrollo socioeconómico y humano (Aguirre: 1995; Figueroa-Pedraza: 2003).

\section{LA ALIMENTACIÓN COMO FACTOR DE CONSTRUCCIÓN DE LA IDENTIDAD Y DE DIFERENCIACIÓN SOCIAL}

A lo largo de milenios la humanidad ha dependido de unas economías agrarias de subsistencia, caracterizadas por su crónica incapacidad de producir suficientes alimentos para la generalidad de la población, por la escasez permanente y las hambrunas cíclicas. Por ejemplo, algunos casos históricos y recientes, en los que esas hambrunas se han manifestado con especial fuerza, son los de Irlanda, Finlandia, India, Burundi, Rusia, Grecia, Madagascar o Japón (Dyson \& O Grada: 2002). Pues bien, durante todo ese tiempo de escasez recurrente de las sociedades agrarias, ha sido normal que las diferencias entre los pobres y los ricos, en lo que a la alimentación se refiere, se hayan manifestado a menudo, como un contraste brutal entre, de una parte, la amenaza de los primeros de morir por inanición o su práctica imposibilidad de acceder a los nutrientes bási$\cos y$, de otra, la virtual opulencia de los segundos y su consiguiente capacidad de comer hasta la saciedad, incluso más allá de sus necesidades biológicas. En cambio, en el actual contexto de superproducción de las agriculturas modernizadas, en el que la globalización hace posible la comercialización a escala planetaria de diversos alimentos, las diferencias entre los pobres y los ricos suelen mostrarse de forma distinta, como se verá a continuación.

En primer lugar, la pobreza ya no se manifiesta, a menudo, como esa inanición y delgadez extremas que podían incluso causar la muerte, sino más bien como una imposibilidad de alimentarse de manera equilibrada $y$ aun poder comer en demasía sólo cierto tipo de alimentos, sufriendo los consiguientes problemas de obesidad. De hecho, en nuestro tiempo es relativamente habitual una gordura característica de las clases bajas ${ }^{2}$. Una gordura que revela que las personas que la padecen tienen posibilidad de comer hasta sentirse saciados pero que, con frecuencia, no impide que esas personas sufran carencias nutricionales básicas como la falta de hierro de las embarazadas, la caída de los dientes debido al escorbuto o deficiencia de vitamina $\mathrm{C}$ o a la falta de higiene. Tales carencias nutricionales son una de las principales causas de que haya una apreciable cantidad de individuos de baja talla, que no han llegado a desarrollar su potencial genético de altura debido a que padecen desnutrición crónica.

No obstante, a medida que las sociedades se desarrollan y se expanden en ellas los

\footnotetext{
Un ejemplo de esto es la obesidad extrema de muchos de los evacuados de Nueva Orleans durante las inundaciones y la devastación que, a finales de agosto de 2005, provocó el huracán Katrina en dicha ciudad. Las imágenes televisivas de tales evacuados, que debido a su pobreza y consiguiente falta de medios propios no habían podido abandonar la ciudad antes de la catástrofe y se habían refugiado en el estadio 'Superdome', resultaron bastante reveladoras de como, incluso en una sociedad rica como la Norteamericana, prolifera esa gordura típica de la escasez entre sus clases bajas.
} 
sectores sociales medios, con niveles socioeconómicos, culturales y adquisitivos más elevados, se observan tendencias hacia una gradual preocupación por la calidad por parte de la generalidad de tales sectores. De esta forma, en contextos en los que la mayoría de la población hace ya tiempo que ha satisfecho sus necesidades biológicas nutricionales básicas, se afianzan cada vez más las actitudes ante el consumo propias de los que viven en una relativa abundancia $y$, por lo tanto, participan de un hedonismo materialista que choca de lleno con los valores de laboriosidad y ahorro que, de acuerdo con Weber (1984), caracterizaban al espíritu del primer capitalismo. Una consecuencia de ello es una desmovilización importante de los asalariados que disfrutan de estas condiciones, como resultado de una transformación de sus expectativas y aspiraciones (Boltanski y Chiapello: 2002, 38). Tales expectativas y aspiraciones ya no se fundamentarían, para muchos de los actuales consumidores, tanto en la opción por unos determinados valores representativos de una ideología sobre el mundo y la sociedad, como en los dilemas y los goces que se derivarían de las mayores posibilidades de elección de bienes que les ofrecen las globalizadas sociedades actuales. Sociedades, en las que se observa una creciente propensión a manifestar, a través de los hábitos que determinan la adquisición y el consumo de alimentos, una cada vez mayor interiorización colectiva de valores y actitudes de índole posmaterialista (Inglehart: 1991).

Sobre todo, estos valores $y$ actitudes ante el consumo alimentario se afianzan entre los sectores sociales medios y altos. En ellos, la gente disfruta de unas condiciones socioeconómicas y culturales que le lleva a ser consciente de que puede elegir y de que el gusto es algo propio de su posición social. Pero, incluso aquellos que tienen niveles bajos de ingresos, cuyo margen de elección es mucho más limitado, suelen también pensar que su sentido del gusto proviene de sus opciones y preferencias individuales. El resultado es que, en realidad, cada sector de ingresos tiende a considerar que sus distintivas formas de alimentación, expectativas $y$ actitudes ante ella son las correctas.
Cada sector social tiene una concepción de qué cuerpo es el ideal y, en razón de ello y de sus posibilidades socioeconómicas, no come cualquier cosa, sino los alimentos que considera le ayudan a acercarse a ese ideal, el cual es muy diferente para cada grupo de ingresos (Shilling: 1993). En este sentido, las clases alta $y$ media no anhelan un cuerpo robusto $y$ más o menos voluptuoso, sino sano, al cual equiparan con un cuerpo delgado. Así, como subraya Patricia Aguirre (1997, 2000, 2001, 2003), los estratos sociales altos y medios han dado en conformar una sociedad "lipófoba" que huye de las grasas. Les preocupa su nivel de colesterol como forma de evitar el infarto o el accidente cerebro-vascular. Para ellos, la delgadez es asociada a la búsqueda de la salud, entendida de forma meritoria: al cuerpo sano se llega mediante un continuo esfuerzo personal. No se trata de realizar dietas transitorias, sino de llevar todo un régimen de vida para salvaguardar la salud. En suma, cada grupo de ingresos desarrolla sus particulares ideas acerca de lo que son sus necesidades básicas de consumo, en función de su visión del propio hecho de alimentarse, de su concepción de la salud $y$, especialmente, de la imagen de belleza corporal con la que se identifica y que pretende constituya su fachada o presentación social en la vida cotidiana (Goffman: 1987).

En lo relativo a las ideas de salud $y$ belleza corporal, como señala Aguirre con referencia al caso de Argentina, el ideal de belleza femenina "en los sectores de ingresos bajos es una mujer de caderas redondeadas, que 'está fuerte'. Son las chicas que (...) no son esmirriadas pero tampoco gordas: tienen tetas, culo, tienen 'de qué agarrarse”" (citada por Flichtentrei: 2006). Y este ideal, según Aguirre, se basa en las propias exigencias del mercado laboral: “CCómo no van a querer un cuerpo fuerte los pobres si los trabajos que pueden tener son de mano de obra intensiva? Un estibador, un albañil, no pueden ser flaquitos, enclenques. Porque el empleador elegirá al de cuerpo 'fuerte'. Y la mujer de este sector social trabajará como personal doméstico, donde la empleadora no elegirá a una chica esmirriada sino a una mujer con fuerza, resistente". De acuerdo con esta consideración 
sobre lo que debe ser su cuerpo y las necesidades funcionales que ha de cumplir, considera Aguirre, que "no es que los pobres 'coman mal': comen según estrategias que desarrollaron para sobrevivir en la pobreza y que efectivamente los mantienen vivos, saciados $y$, aunque con deficiencias, nutridos. Y ellos no perciben esa 'gordura' como disfuncional ¿Cómo le vas a decir a esa mujer de caderas generosas que ella está desnutrida? Desde el punto de vista de su entorno, es el cuerpo que hay que tener" (citado por Flichtentrei: 2006).

Por otra parte, con referencia a la visión del hecho de alimentarse, se manifiestan también actitudes distintas entre los diferentes sectores sociales. Esto lo pone de manifiesto Aguirre al contarnos como, cuando va a las casas a hacer entrevistas y llega la hora de la comida del mediodía, en los sectores de ingresos bajos la suelen invitar a comer. En cambio, en los sectores medios y altos, a las 12 o las 12:30 aparece cierta inquietud y apuro, pero ni por asomo se les ocurre invitarla a comer. Como la propia Aguirre sugiere, los sectores con ingresos bajos suelen pensar que todo el que está en su casa a la hora de comer puede compartir su comida. Y así resulta muy funcional la comida del pobre, "porque se estira: a la olla siempre se le puede agregar un poco de agua, un poco de fideos". Por el contrario, para las clases medias, el hecho de comer es un evento familiar al que sólo se puede acceder con una invitación previa.

Por último, en las clases altas, también de acuerdo con Aguirre, la comida suele ser un hecho individual, en el que la preocupación por la salud desempeña una función primordial. Un hecho, en el que ya se ha perdido la idea de la necesidad de compartir la mesa con todos los presentes. La individualidad de este hecho puede llegar al grado de que haya una mesa familiar con cuatro comidas distintas: la del padre, que es una dieta para evitar el exceso de colesterol; la de la madre, que come ensalada verde para estar delgada y bella; la de la hija, que es macrobiótica y come arroz integral; la del hijo, que practica deporte de alta competición (citado por Flichtentrei: 2006). En suma, cada uno, de acuerdo con su trabajo o situación específica, lleva a cabo una dieta personalizada (Golay: 2000).

La referida tendencia hacia la individualización de la comida rompe con lo que ha sido nuestra ancestral tradición como especie. Al fin $y$ al cabo, nos hicimos humanos compartiendo la comida, de tal forma que hace 2,5 millones de años el omnivorismo obligó a nuestros antepasados a conseguir la comida en grupo, ya que, al carecer de las garras o caninos de los leones o de la rapidez de los monos, la manera de obtener proteínas se basó en la cooperación del grupo, en la suma de esfuerzos individuales.

En un mundo, en el que cada vez más la comida es un hecho individual y el comensal un solitario, no conviene perder de vista que, en tanto que humanos, el hecho de comer no sólo tiene como función primordial proporcionarnos la nutrición necesaria, sino que también es un acto dotado de un sentido cultural, a la vez que productor $y / 0$ fortalecedor de los vínculos de sociabilidad. Por ello, la anomia del, a menudo solitario, comensal del globalizado mundo moderno constituye un síntoma característico de nuestro tiempo, una de las causas del malestar psicosocial actual. De este modo, a la crisis de equidad en la distribución de los alimentos que existe a escala planetaria y que propicia que una gran parte de la humanidad sufra el hambre y la desnutrición, hay que añadir esa otra crisis humana de anomia que deriva de la pérdida de la sociabilidad del hecho de comer a raíz de su progresiva individualización.

\section{CONSIDERACIONES FINALES}

En el mundo crecientemente interconectado que propicia la globalización, en el que se generalizan y afianzan cada vez más las preocupaciones por la salud y por lo ecológico, al mismo tiempo que la publicidad y los medios de comunicación de masas suelen difundir planetariamente imágenes muy similares acerca del cuerpo ideal y del estilo de vida anhelable, los efectos de la globalización alimentaria y/o las reacciones ante ella no se manifiestan, sin embargo, de manera homogénea, sino que lo hacen de modo distinto según cada clase social 
o grupo de ingresos, cada uno de los cuales desarrolla unos diferenciados hábitos de alimentación y considera como deseables unas imágenes específicas del cuerpo, en consonancia con su particular forma y expectativas de vida (Bourdieu: 1971).

La observación de las antedichas diferencias en los hábitos alimentarios de los distintos sectores sociales manifiesta cómo esos hábitos se erigen en factores de construcción de la identidad individual o colectiva $y$ de distinción social. Durante milenios, en las sociedades insertas en economías de auto-subsistencia, dicha construcción y distinción se solían mostrar a través de la mayor o menor disponibilidad de alimentos. Sin embargo, para un gran número de personas, esto no es ya así en el presente contexto de abundancia, en el que, a pesar de que todavía una gran parte de la población mundial sufre la desnutrición, el hambre y la inanición más extremas, otra importante proporción de esa población tiene acceso a muchos más alimentos de los que necesita para subsistir. Para esta parte más afortunada de la humanidad, son las características de sus propios hábitos de alimentación las que manifiestan las diferencias entre los distintos sectores de ingreso. Como consecuencia, la construcción de la identidad y la distinción social, así como el habitus o las actitudes inherentes a las diferencias de clase o status (Bourdieu: 1988), que todo ello conlleva en lo que a la alimentación se refiere, no se simbolizan ya, para muchos, tanto por la posibilidad de no "pasar hambre", como por la circunstancia de gozar de una situación socioeconómica que les permite comer de manera sana y equilibrada e, incluso, entre una proporción de consumidores con niveles socioculturales medios o altos, mostrar unas actitudes consumistas como sujetos sociales activos (Callejo: 1995). Tales actitudes, en algunos casos, se traducen en el desarrollo de preocupaciones cívicas y sociales que les llevan, por ejemplo, a preferir la adquisición de productos y marcas en cuya elaboración no se ha utilizado mano de obra infantil, ni han existido condiciones de contratación injustas o salarios indignos $y$ tampoco se ha amenazado la seguridad, los empleos o el medio ambiente (Barber: 2001, 112).

En cualquier caso, hoy por hoy, dichas preocupaciones cívicas no dejan de ser actitudes minoritarias de ciertos grupos "concienciados" y, por lo tanto, opciones más o menos testimoniales. Conseguir que el consumo de bienes alimentarios sea un ejercicio cívico, aunque sólo fuera para la generalidad de esa parte de la población mundial que está en condiciones de determinar soberanamente sus hábitos alimentarios, requeriría una transformación de las estructuras socioeconómicas que permitiera el afianzamiento de una concepción del mercado alimentario, no sólo como un simple lugar de intercambio de mercancías, sino también como parte de interacciones socioculturales más complejas. Interacciones, a partir de las que se hiciera posible que el consumo alimentario fuera visto, además de como un hecho individual o grupal (motivado por las necesidades biológicas y producto/productor de significación sociocultural), como una estrategia tendente a intentar la reconquista imaginativa de los espacios colectivos y el interés por lo público. Así, ese consumo se mostraría como un hecho útil para pensar y actuar significativa y renovadoramente en la vida social (García Canclini: 1995).

Lejos de eso, particularmente entre muchos de los pertenecientes a los sectores sociales con niveles de ingresos medios $y$ altos, sucede a menudo, como hemos visto antes, que el hecho de adquirir y consumir alimentos es, sobre todo, una expresión de su estilo de vida, una manera de conseguir el cuerpo y el ideal de salud anhelados, a la vez que una ocasión de mostrar su interiorización del habitus del "buen gusto" y la "distinción" (Bourdieu: 1976). "Habitus" y "distinción" cuyo logro implica, por lo tanto, la posesión de un nivel sociocultural que haga posible una considerable planificación y elección de las conductas y las actitudes vitales, en este caso las relativas a la propia alimentación. Pero, esto no es incompatible con el hecho de que los hábitos de consumo alimentario de tales sectores sociales se realicen, frecuentemente, de acuerdo con esquemas conductuales encuadrables dentro de lo que 
Baudrillard (1976) ha conceptuado como la génesis ideológica de las necesidades; es decir, no se desarrollan de modo completamente libre, sino bajo el influjo de unas ideologías, fomentadas, por ejemplo, a través de la seducción que ejercen los discursos de determinados "peritos" alimentarios divulgados sobre las conciencias a través de medios o formas de comunicación de carácter relativamente selectivo o elitista. Ideologías que constituyen, a su vez, las bases de sustentación de diferentes demostraciones de riqueza de aquellos que pueden desarrollar formas de consumo ostensible muy similares a las descritas por Veblen (1987: 72 y ss.), a través de las que se trata de evidenciar un acceso o disfrute diferenciado a ciertos productos que, independientemente de su valor intrínseco, han sido revestidos simbólicamente de singularidad $y$ cierta distinción.

No obstante, en contraste con lo antedicho, es un hecho inapelable que el patrón "mcdonalizado" y masificado de consumo alimentario continúa siendo dominante para la gran mayoría de la población mundial. Sobre todo, dicho patrón se manifiesta de manera particularmente intensa entre los colectivos más vulnerables o influenciables como, por ejemplo, en los niños y los jóvenes, así como en todos aquellos con niveles socioeconómi$\cos y / 0$ educativos más bajos, tales como los estratos inferiores de las clases medias, los parados de larga duración o los inmigrantes en trance de ser aculturados (Alonso: 2002). Sectores sociales todos ellos que, debido a su menor poder adquisitivo, estarían especialmente predispuestos a desarrollar esas formas de obesidad con carencias nutricionales básicas referidas antes como típicas de los más pobres. En tales circunstancias, los hábitos de consumo alimentario, en vez de algo producido ideológicamente, suelen manifestar una génesis, con frecuencia impulsiva o emocional, motivada por la "necesidad" instantánea que suscitan los mensajes publicitarios audiovisuales o gráficos destinados a promocionar la mercantilización de los alimentos.

De todas formas, independientemente de que sea una actitud consciente $y$ deliberadamente planificada o una conducta masiva o "mcdonalizada" inducida por la publicidad, en ambos casos el consumo alimentario se manifiesta como una pauta o práctica socialmente construida; en suma, como un habitus que se produce $y$ reproduce en el contexto de unas condiciones sociales específicas. Tradicionalmente, dicho habitus solía ser transmitido hereditariamente mediante procesos de socialización de clase o de status, de los que por lo general se encargaba la familia. En nuestros días, la televisión y la publicidad, para el común de las gentes (Botey-López y Murillo-Fort: 2006), o las revistas "prestigiosas" y el consejo de los "entendidos", así como la emulación de determinados grupos de referencia revestidos de prestigio por parte de los que ahora aspiran a la exquisitez (y, en definitiva, a la "distinción"), están ocupando crecientes parcelas de ese papel formador de clase o de status otrora asumido en exclusiva por la institución familiar y/o por los grupos primarios de socialización básica.

Y, la influencia mundial de los mass media es una de las principales causas de la actual globalización de los hábitos agroalimentarios, lo cual se manifiesta en el hecho de la producción y reproducción social, a escala planetaria, de maneras bastante uniformes de cultivo y elaboración de los alimentos. Esta situación favorece que los hábitos de consumo alimentario estén, en muy gran medida, determinados por las directrices de las grandes corporaciones transnacionales, lo que suele ir asociado a una gradual merma de la soberanía alimentaria de las poblaciones locales.

No obstante, la globalización conlleva también un aumento sin precedentes de las oportunidades de contacto $y$ de comercio al nivel mundial, lo que posibilita el cultivo y el consumo de muchos productos autóctonos a gran distancia de sus lugares tradicionales de origen, es decir, ese cultivo y consumo se desterritorializan notablemente. Una muestra de ello es que un creciente mercado de productos exóticos está ahora fácilmente al alcance de los consumidores en sus respectivos entornos cotidianos. Sobre todo, los productos exóticos expanden su mercado en el mundo desarrollado, en el que una importante fracción de sus consumidores tiene capacidad de compra 
suficiente como para plantearse su adquisición. En concreto, en la Unión Europea los consumidores exigen una disponibilidad cada vez mayor de alimentos exóticos a lo largo de todo el año (Chavarrías: 2006).

La creciente demanda de esos alimentos está muy favorecida por la cada vez mayor preocupación, que se manifiesta en los hábitos alimentarios de las clases medias y altas, por la búsqueda de la singularidad, la diversidad, la salud y/o la calidad. Particularmente, el concepto de calidad es ambiguo e impreciso y suscita diversas interpretaciones. Por ejemplo, a veces, los productos a los que se les atribuye mayor calidad son los de "agricultura ecológica", los que su consumo evoca sensaciones de "vuelta a la naturaleza"; sensaciones cuyo fuerte arraigo actual se explicaría por el hecho de que en los ambientes urbanos (en los que preponderantemente habita hoy la población mundial) se vive más lejos de la naturaleza que nunca antes. Otras veces, la circunstancia de ser consumidos en determinados restaurantes selectos es interpretada como un signo de la calidad de ciertos productos, la cual también es asociada, muy a menudo, con el hecho de que algunos alimentos sean elaborados, cultivados o "diseñados" en régimen agro-industrial ${ }^{3}$.

La búsqueda de la calidad, en cualquiera de las formas mencionadas u otras, conlleva además la búsqueda de la singularidad y la distinción de aquellos que optan por una determinada modalidad de consumo. Una búsqueda que se manifiesta también, por ejemplo, mediante la referida demanda mundial creciente de productos exóticos y ecológicos. Por lo tanto, dadas las muy variadas maneras posibles de entender la calidad, su búsqueda a través de la opción por cualquiera de los diversos modos de consumo alimentario, erige a éste en un hecho social diferenciador y único para

La búsqueda del diseño es observable, incluso, en esas maneras de cultivar tendentes a que el producto adquiera una determinada forma. Por ejemplo, tomates, manzanas u otros frutos que se comercializan con figuras geométricas casi perfectamente regulares. cada persona, sector o grupo social específicos. Un hecho que, en el mundo cada vez más homogeneizado de la globalización, constituye una de las señales de distinción y / o identidad social, así como del nivel socioeconómico, la posición de clase, el status o el estilo de vida de tal persona, sector o grupo.

\section{BIBLIOGRAFÍA}

Aguirre, Patricia. "Papel de las estrategias domésticas de consumo en el acceso a los alimentos". Archivos Latinoamericanos de Nutrición 45. 1. 1995: 341-350.

"Patrón alimentario, estrategias de consumo e identidad en Argentina". Boletín Informativo Techint 290. 1997: 89-104.

. "Aspectos antropológicos de la obesidad en la pobreza". Peña, M. y Bacallao, J. (Comps.) La obesidad en la pobreza: un nuevo reto para la salud pública OPS-OMS 576. Publicación Científica, edición bilingüe. Washington, EE.UU. 2000.

"Los alimentos Rendidores y el Cuerpo de los pobres". Antropología de la alimentación. Arbitrario cultural y alimentación. Homenaje al Dr. Igor de Garine. Amado A. Millán Fuertes (compilación), ICAF (Comisión Internacional para la Antropología y la Alimentación). Borja, España. 2001.

"Gordos de Escasez, las consecuencias de la cocina de la pobreza". La cocina como patrimonio (in)tangible. Primeras Jornadas de Patrimonio Gastronómico. Secretaría de Cultura de la Ciudad de Buenos Aires, 2003.

Alonso, Luis Enrique. "¿Un nuevo consumidor?”. Ábaco: Revista de Cultura y Ciencias Sociales 31. $2^{\text {a }}$ época. 2002: 11-18. 
Altieri, Miguel; y Nicholls, Clara. "Una perspectiva agroecológica para una agricultura ambientalmente sana $y$ socialmente más justa en la América Latina del siglo xxI”. Leff, E. y otros (comps.) La transición hacia el desarrollo sustentable. Perspectiva para América Latina y el Caribe. Secretaría de Medio Ambiente y Recursos Naturales (SEMARNAT). Instituto Nacional de Ecología, 2002: 286-289.

Arribas, Leopoldo. "El control de la producción de alimentos". Phytoma España: La revista profesional de sanidad vegetal 166. 2005: 10-11.

Barber, J. (1998). A Place for Us. Nueva York: Farrar/Pantheon Books, 2001.

Baudrillard, Jean. La génesis ideológica de las necesidades. Barcelona: Anagrama, 1976.

Beck, Ulrich. "De la sociedad industrial a la sociedad del riesgo. Cuestiones de supervivencia, estructura social e ilustración ecológica”. Revista de Occidente 150. Madrid, 1993: 19-40.

Berger, Peter; y Luckmann, Thomas. (1966). La construcción social de la realidad. Buenos Aires: Amorrortu, 1979.

Boltanski, Luc; y Chiapello, Eve. El nuevo espíritu del capitalismo. Madrid: Akal, 2002.

Botey-López, Jordi; y Murillo-Fort, Ignasi. "La promesa publicitaria en las marcas de alimentación. Una visión estratégica”. Nutrición Clínica 6. 2006: 16-22.

Bourdieu, Pierre. "Champ du pouvoir, Champ intéllectuel et habitus de classe". Scolies 1. 1971: 7-26.

"Anatomie du goût". Actes de la recherche en sciences sociales 11. 1976: 2-112 (con M. de Saint Martin).
- La distinción. Criterio y bases sociales del gusto. Madrid: Taurus, 1988.

Callejo, Javier. "Elementos para una teoría sociológica del consumo". Papers 47. 1995: 75-96.

Chavarrías, Marta. "Alimentos exóticos en la UE". Consumer.es. 3-8-06, Fundación Eroski. 2006 . En: <http://www. consumaseguridad.com/web/es/sociedad _y_consumo/2006/08/03/24413.php> [Consultado: 3/08/06].

Díaz-Méndez, Cecilia; y Gómez-Benito, Cristóbal. "Del consumo alimentario a la sociología de la alimentación". Distribución y Consumo 60. año 11. 2001: 5-24.

Dyson, Tim; O Grada, Cormac (Editors). Famine Demography: Perspectives from the Past and Present. USA: Oxford University Press, 2002.

Eder, Klaus. The social construction of nature. A sociology of ecological enlightenment. Londres: Sage Publications, 1996.

Fereres, Alberto. "Combatir las plagas sin contaminar". Ecosistemas 7. 1993: 30-34.

Figueroa-Pedraza, Dixis. "Seguridad alimentaria familiar". RESPYN. Revista de Salud Pública y Nutrición 4.2. 2003. En: $<$ http://www.respyn.uanl.mx/iv/2/index. html>

Flichtentrei, Daniel (2006) “¿Por qué comemos lo que comemos?". Entrevista a Patricia Aguirre. IntraMed. En: <http://www. abcpediatria.com $>$ [Consultado:8/04/06]

García Canclini, Néstor. Consumidores y ciudadanos. Conflictos multiculturales de la globalización. México: Grijalbo, 1995. 
Goffman, Erving. (1959) La presentación de la persona en la vida cotidiana. Buenos Aires: Amorrortu-Murgía, 1987.

Golay, Alain. La dieta personalizada: adelgace según su personalidad. Barcelona: Ediciones Omega, S.A. 2000.

Inglehart, Ronald. El cambio cultural en las sociedades industriales avanzadas. Madrid: CIS/s XXI, 1991.

Machado, Absalón; y Torres O., Jorge. Sistema agroalimentario: una visión integral de la cuestión agraria en América Latina. Bogotá (Colombia): Siglo XXI, 1987.

Mcmichael, Philip D. (Editor). The global restructuring of agro-food systems (Food systems and agrarian change). Ithaca. Nueva York: Cornell University Press, 1994.

Molina, Luisa Elena. "Reflexiones sobre la seguridad alimentaria y la situación alimentaria internacional". Revista agroalimentaria 15. 2002: 89-99.
Riverón-Corteguera, Raúl. "Valor inmunológico de la leche materna". Revista Cubana de Pediatría 67.2. 1995: 116-133.

Shilling, Chris. The body and social theory. London: Sage Publications, 1993.

Veblen, Thorstein. (1899) Teoría de la clase ociosa. Barcelona: Ediciones Orbis S.A. 1987.

Vera, José Fernando; y Romero, Joan. "Impacto ambiental de la actividad agraria". Agricultura y Sociedad 71. 1994: 153181.

Vía Campesina. ¿Qué significa soberanía alimentaria?. En: <http://www. viacampesina.org/main_sp/index. php?option $=$ com_content $\&$ task $=v i e$ $w \& \mathrm{id}=78 \&$ Itemid $=27>$ Wednesday, 15 January 2003.

Weber, Max (1903). La ética protestante y el espíritu del capitalismo. Madrid: Sarpe, 1984. 